EVIDENCE BASED PUBLIC HEALTH POLICY AND PRACTICE

\title{
Physical activity and health related quality of life among people with arthritis
}

\author{
Jill E Abell, Jennifer M Hootman, Matthew M Zack, David Moriarty, Charles G Helmick
}

J Epidemiol Community Health 2005;59:380-385. doi: 10.1136/jech.2004.028068

See end of article for authors' affiliations

Correspondence to:

Dr J M Hootman, Division of Adult and Community Health, Centers for Disease Control and Prevention, 4770 Buford Highway NE, Mailstop K-51, Atlanta, GA 30341, USA; jhootman@cdc.gov

Accepted for publication 17 December 2004

\begin{abstract}
Study objective: To assess the association between physical activity and health related quality of life (HRQOL) among persons with arthritis or chronic joint symptoms (CJS).

Design: Cross sectional survey investigating the relation between physical activity level and HRQOL. $\mathrm{HRQOL}$ was estimated using the number of physically or mentally unhealthy days during the past 30 days. Physical activity was categorised as recommended, insufficient, or inactive according to federal activity recommendations. Persons with arthritis were defined as those with either self reported CJS or doctor diagnosed arthritis.

Setting: Community dwelling, US adults residing in all 50 states and the District of Columbia.

Participants: Respondents $(n=212$ 000) in the 2001 behavioral risk factor surveillance system (BRFSS), an annual population based, telephone survey.

Main results: The $33 \%$ of BRFSS respondents with arthritis had a mean of 6.7 physically and 4.9 mentally unhealthy days during the past 30 days, compared with 1.8 and 2.7 among those without arthritis. Inactive men and women were 1.2-2.4 times more likely to report impaired HRQOL compared with those who met physical activity recommendations. Men and women who engage in insufficient physical activity also report variably reduced $H R Q O L$.

Conclusions: Among people with arthritis, recommended levels of physical activity were associated with fewer mean physically and mentally unhealthy days and a decreased probability of having severely impaired physical or mental HRQOL.
\end{abstract}

A rthritis, the leading cause of disability, ${ }^{1}$ has been described as one of the most pressing public health problems. ${ }^{2}$ In 2001, an estimated 70 million Americans reported having arthritis or chronic joint symptoms (CJS). ${ }^{3}$ In 1997, arthritis cost the nation an estimated $\$ 86$ billion in direct and indirect expenditures. ${ }^{4}$ By 2030, with the expected aging of the population, arthritis prevalence is estimated to grow even larger.

Health related quality of life (HRQOL) is a good indicator of the impact of arthritis because arthritis seldom causes death but causes pain and substantially affects function. ${ }^{6}$ Persons with arthritis report more physically and/or mentally unhealthy days than those without arthritis, regardless of sex, age, or educational level. ${ }^{6}$ Compared with those without arthritis, persons with arthritis reported an average of 4.0 more days during the previous 30 days when physical health was not good and an average of 2.3 more days when mental health was not good. ${ }^{6}$

Regular physical activity can reduce arthritis related pain, improve function, and delay disability without promoting disease progression among persons with arthritis. ${ }^{78}$ Physical activity (PA) is also associated with improved quality of life among older adults. ${ }^{9}$ Despite these benefits, persons with arthritis are not as physically active as those without arthritis. ${ }^{10}$ Nationally, the very groups experiencing the greatest burden of arthritis-women, older adults, and those with less education-also consistently participate less often in PA. ${ }^{11}$

The relation between PA and HRQOL has not been adequately explored in the general population or among those with arthritis or CJS. We used data from the 2001 behavioral risk factor surveillance system (BRFSS) to assess the association between PA and HRQOL, defined as the number of physically or mentally unhealthy days, among persons with and without arthritis or CJS.

\section{METHODS}

The BRFSS is a state based survey designed to gather uniform, state specific data on preventive health practices and risk behaviours linked to chronic disease, injuries, and preventable infectious diseases in the adult population. Data are collected from a sample of adults aged 18 years or older (one per household) through a random digit dialled telephone interview conducted by a trained and monitored interviewer. All states and territories in 2001 used an identical core questionnaire that includes our variables of interest. The BRFSS survey protocol is annually reviewed and approved by the CDC Institutional Review Board. More information on the design and methods of the BRFSS is available at http://www.cdc.gov/brfss/about.htm.

Persons with arthritis or CJS (hereafter termed arthritis) were defined as those with either self reported (CJS) or doctor diagnosed arthritis. A person had CJS if they answered "Yes" to both of the following questions: (1) "During the past 12 months, have you had pain, aching, stiffness or swelling in or around a joint?" and (2) "Were these symptoms present on most days for at least one month?" Persons were considered to have doctor diagnosed arthritis if they answered "Yes" to the following question: "Have you ever been told by a doctor that you have arthritis?"

To determine the level of PA, respondents were asked about their participation in non-occupational, moderate, and/ or vigorous physical activity for at least 10 minutes at a time in a usual week. Moderate activity was defined as any activity, including leisure time, household, or transportation, that causes a small increase in breathing or heart rate (such as brisk walking, bicycling, vacuuming, or gardening).

Abbreviations: $H R Q O L$, health related quality of life; CJS, chronic joint symptoms; BRFSS, behavioral risk factor surveillance system; PA, physical activity 
Vigorous activity was defined as any activity that causes a large increase in breathing or heart rate (such as running, aerobics, or heavy yard work). Respondents were classified into three levels of PA: (1) inactive-no PA; (2) insufficientthose who reported some activity, but not at recommended levels; and (3) recommended-those who met either the moderate PA recommendation (at least 30 minutes of moderate intensity PA at least five days per $w^{2} \mathrm{k}^{12}$ ) or the vigorous recommendation (at least 20 minutes of vigorous intensity at least three days per week ${ }^{13}$ ). These questions have shown moderate to high reliability and validity. ${ }^{14}$

The HRQOL outcome variables of interest were recent physically and mentally unhealthy days. Physically unhealthy days were estimated using the BRFSS question: "Now thinking about your physical health, which includes physical illness and injury, for how many days during the past 30 days was your physical health not good?" Mentally unhealthy days were estimated from a similar question: "Now thinking about your mental health, which includes stress, depression and problems with emotions, for how many days during the past 30 days was your mental health not good?" These two
HRQOL questions globally measure recent physical health symptoms and recent mental and emotional distress. ${ }^{15}$ These BRFSS HRQOL questions have been validated by statistically correlating the responses with measures from other more comprehensive or established instruments such as the medical outcomes short form 36 (SF-36). The HRQOL measures used in the BRFSS have good construct and acceptable criterion and known groups validity and have been suggested for use in surveillance and research. ${ }^{15} 16$

The following categorical covariates were used to control for confounding between physical activity level and HRQOL: sex; age $(18-44,45-64$, or 65 years old or older); race and ethnicity (non-Hispanic white, non-Hispanic black, nonHispanic other, or Hispanic); marital status (married, nonmarried couple, single, separated, divorced, or widowed); educational attainment (less than high school graduate or high school graduate or more); employment status (employed/self employed, student/homemaker, unemployed, unable to work, or retired); annual household income $(<\$ 25000, \$ 25000$ to $\$ 49999, \geqslant \$ 50000$, missing); body mass index $\left(\mathrm{BMI}=\right.$ weight kilograms/height metres ${ }^{2}$;

Table 1 Study characteristics of persons with and without arthritis or CJS, BRFSS 2001

\begin{tabular}{|c|c|c|c|c|}
\hline Characteristic & $\begin{array}{l}\text { With arthritis* } \\
\text { ( } n=69 \text { million) }\end{array}$ & $\begin{array}{l}\text { No arthritis* } \\
\text { ( } n=140 \text { million) }\end{array}$ & Odds ratio† & $(95 \% \mathrm{Cl}) \dagger$ \\
\hline Sex & $\%$ & $\%$ & & \\
\hline Female & 58.7 & 51.4 & 1.5 & (1.5 to 1.6$)$ \\
\hline Male & 41.3 & 48.6 & 1.0 & \\
\hline \multicolumn{5}{|l|}{ Age (y) } \\
\hline $18-44$ & 29.6 & 63.0 & 1.0 & \\
\hline $45-64$ & 39.2 & 26.4 & 3.2 & (3.0 to 3.3 ) \\
\hline $65+$ & 31.2 & 10.7 & 6.2 & (6.0 to 6.5 ) \\
\hline \multicolumn{5}{|l|}{ Body mass index } \\
\hline Underweight & 1.7 & 2.2 & 1.0 & (0.9 to 1.2 ) \\
\hline Normal weight & 31.6 & 43.1 & 1.0 & \\
\hline Overweight & 37.6 & 36.8 & 1.4 & (1.3 to 1.5 ) \\
\hline Obese & 29.2 & 17.8 & 2.2 & (2.1 to 2.3 ) \\
\hline \multicolumn{5}{|l|}{ Race and ethnicity } \\
\hline Non-Hispanic white & 76.2 & 68.5 & 1.0 & \\
\hline Non-Hispanic black & 8.9 & 9.7 & 0.8 & (0.8 to 0.9$)$ \\
\hline Non-Hispanic other & 5.4 & 6.9 & 0.7 & (0.7 to 0.8$)$ \\
\hline Hispanic & 9.5 & 14.9 & 0.6 & (0.5 to 0.6$)$ \\
\hline \multicolumn{5}{|l|}{ Marital status } \\
\hline Married & 59.3 & 58.5 & 1.0 & \\
\hline Widowed & 12.7 & 4.3 & 2.9 & ( 2.8 to 3.1 ) \\
\hline Divorced & 12.5 & 8.7 & 1.4 & (1.3 to 1.5 ) \\
\hline Separated & 2.6 & 2.2 & 1.1 & (1.0 to 1.3 ) \\
\hline Never married & 10.7 & 22.7 & 0.5 & (0.4 to 0.5 ) \\
\hline Couple, unmarried & 2.3 & 3.7 & 0.6 & (0.6 to 0.7$)$ \\
\hline \multicolumn{5}{|l|}{ Educational attainment } \\
\hline High school graduate & 83.2 & 88.7 & 1.0 & \\
\hline Less than high school & 16.8 & 11.4 & 1.6 & (1.5 to 1.7 ) \\
\hline \multicolumn{5}{|l|}{ Employment status } \\
\hline Employed/self employed & 48.4 & 70.3 & 1.0 & \\
\hline Unemployed & 4.4 & 4.3 & 1.5 & (1.4 to 1.6$)$ \\
\hline Student/homemaker & 9.4 & 13.2 & 1.0 & (1.0 to 1.1 ) \\
\hline Retired & 28.7 & 10.6 & 3.9 & (3.8 to 4.1 ) \\
\hline Unable to work & 9.2 & 1.6 & 8.2 & (7.4 to 8.9 ) \\
\hline \multicolumn{5}{|l|}{ Income } \\
\hline$<\$ 25000$ & 36.7 & 25.8 & 1.9 & (1.8 to 2.0$)$ \\
\hline$\$ 25000-\$ 49999$ & 32.5 & 33.4 & 1.3 & (1.2 to 1.4$)$ \\
\hline$\geqslant \$ 50000$ & 30.8 & 40.8 & 1.0 & \\
\hline \multicolumn{5}{|l|}{ Smoking status } \\
\hline Non-smoker & 45.5 & 56.4 & 1.0 & \\
\hline Former smoker & 30.9 & 21.2 & 1.8 & (1.7 to 1.9$)$ \\
\hline Current smoker & 23.5 & 22.3 & 1.3 & (1.3 to 1.4$)$ \\
\hline \multicolumn{5}{|l|}{ Physically unhealthy days } \\
\hline 0 days & 51.2 & 72.8 & 1.0 & \\
\hline $1-13$ days & 26.1 & 22.7 & 1.6 & (1.6 to 1.7 ) \\
\hline $14-30$ days & 22.8 & 4.5 & 7.2 & (6.8 to 7.6$)$ \\
\hline \multicolumn{5}{|l|}{ Mentally unhealthy days } \\
\hline 0 days & 61.1 & 68.1 & 1.0 & \\
\hline $1-13$ days & 23.2 & 24.6 & 1.1 & (1.0 to 1.1$)$ \\
\hline $14-30$ days & 15.8 & 7.3 & 2.4 & ( 2.3 to 2.6 ) \\
\hline
\end{tabular}


Table 2 Characteristics of persons with arthritis (no arthritis) and odds of arthritis by level of physical activity, BRFSS 2001

\begin{tabular}{|c|c|c|c|c|c|c|c|c|c|}
\hline \multirow[b]{3}{*}{ Characteristics } & \multicolumn{9}{|c|}{ Physical activity level } \\
\hline & \multicolumn{3}{|c|}{ Recommended } & \multicolumn{3}{|c|}{ Insufficient } & \multicolumn{3}{|l|}{ Inactive } \\
\hline & $\%$ Arth & $\%$ No Arth & $\mathrm{OR}(95 \% \mathrm{Cl})$ & $\%$ Arth & $\%$ No Arth & $\mathrm{OR}(95 \% \mathrm{Cl})$ & $\%$ Arth & $\%$ No Arth & $\mathrm{OR}(95 \% \mathrm{Cl})$ \\
\hline Overall & 40.0 & $(50.0)$ & 1.0 (referent) & 38.0 & $(39.0)$ & $1.2(1.1$ to 1.2$)$ & 22.0 & (13.0) & $2.0(1.9$ to 2.1$)$ \\
\hline \multicolumn{10}{|l|}{ Sex } \\
\hline Female & 36.9 & $(46.1)$ & $1.3(1.3$ to 1.4$)$ & 40.1 & $(40.4)$ & $1.7(1.6$ to 1.7$)$ & 23.0 & $(13.6)$ & $2.8(2.7$ to 3.0$)$ \\
\hline Male & 44.5 & $(49.7)$ & 1.0 (referent) & 35.5 & $(37.7)$ & $1.1(1.0$ to 1.1$)$ & 20.0 & $(12.5)$ & $1.8(1.7$ to 1.9$)$ \\
\hline \multicolumn{10}{|l|}{ Age $(y)$} \\
\hline $18 t-44$ & 48.2 & $(50.4)$ & 1.0 (referent) & 37.4 & $(38.7)$ & $1.0(1.0$ to 1.1$)$ & 14.4 & $(10.9)$ & $1.4(1.3$ to 1.5$)$ \\
\hline $45-64$ & 38.5 & $(44.5)$ & $2.8(2.7$ to 3.0$)$ & 40.9 & $(41.6)$ & $3.2(3.0$ to 3.4$)$ & 20.7 & (13.9) & $4.9(4.5$ to 5.3$)$ \\
\hline $65+$ & 34.0 & $(41.8)$ & $5.3(4.9$ to 5.7$)$ & 35.4 & (33.9) & $6.9(6.4$ to 7.4$)$ & 30.6 & (24.3) & $8.3(7.7$ to 9.0$)$ \\
\hline \multicolumn{10}{|l|}{ Body mass index } \\
\hline Underweight $(<18.5)$ & 36.7 & $(45.7)$ & $0.9(0.8$ to 1.1$)$ & 33.7 & (34.4) & $1.1(0.9$ to 1.5$)$ & 29.6 & (19.9) & $1.7(1.4$ to 2.2$)$ \\
\hline Normal weight (18.5-24.9) & 46.6 & (52.4) & 1.0 (referent) & 35.5 & $(36.7)$ & $1.1(1.0$ to 1.2$)$ & 17.9 & (11.0) & $1.8(1.7$ to 2.0$)$ \\
\hline Overweight (25-29.9) & 42.1 & $(48.8)$ & $1.4(1.3$ to 1.4$)$ & 38.3 & $(39.1)$ & $1.5(1.5$ to 1.6$)$ & 19.6 & (12.1) & $2.5(2.3$ to 2.7$)$ \\
\hline Obese $(30+)$ & 31.8 & (38.6) & $2.1(1.9$ to 2.2$)$ & 41.8 & $(45.0)$ & $2.3(2.2$ to 2.5$)$ & 26.4 & (16.4) & $4.0(3.7$ to 4.4$)$ \\
\hline \multicolumn{10}{|l|}{ Race and ethnicity } \\
\hline Non-Hispanic white & 42.1 & $(50.7)$ & 1.0 (referent) & 38.4 & $(39.0)$ & $1.2(1.2$ to 1.2$)$ & 19.5 & $(10.3)$ & $2.3(2.2$ to 2.4$)$ \\
\hline Non-Hispanic black & 28.1 & (39.8) & $0.7(0.6$ to 0.8$)$ & 38.9 & $(40.1)$ & $1.0(0.9$ to 1.1$)$ & 32.9 & $(20.0)$ & $1.7(1.5$ to 1.9$)$ \\
\hline Non-Hispanic other & 40.3 & (44.8) & $0.8(0.7$ to 0.9$)$ & 39.0 & $(40.4)$ & $0.8(0.7$ to 1.0$)$ & 20.8 & (14.9) & $1.2(1.0$ to 1.5$)$ \\
\hline Hispanic & 35.3 & $(42.0)$ & $0.6(0.5$ to 0.7$)$ & 35.7 & $(37.8)$ & $0.7(0.6$ to 0.8$)$ & 29.0 & $(20.2)$ & $1.0(0.9$ to 1.2$)$ \\
\hline \multicolumn{10}{|l|}{ Marital status } \\
\hline Married & 41.4 & $(46.7)$ & 1.0 (referent) & 39.7 & $(40.1)$ & $1.1(1.0$ to 1.2$)$ & 18.9 & (12.4) & $1.7(1.6$ to 1.8$)$ \\
\hline Divorced & 38.0 & $(47.2)$ & $1.3(1.2$ to 1.4$)$ & 37.4 & (38.2) & $1.6(1.4$ to 1.7$)$ & 24.6 & (14.5) & $2.7(2.4$ to 3.0$)$ \\
\hline Widowed & 29.9 & (36.8) & $2.7(2.5$ to 3.0$)$ & 34.0 & (37.2) & $3.1(2.8$ to 3.4$)$ & 36.2 & $(26.0)$ & $4.7(4.3$ to 5.2$)$ \\
\hline Separated & 36.1 & (45.3) & $1.1(0.9$ to 1.3$)$ & 35.8 & (37.3) & $1.3(1.0$ to 1.5$)$ & 28.1 & (17.3) & $2.1(1.7$ to 2.7$)$ \\
\hline Never married & 44.9 & (53.1) & $0.5(0.4$ to 0.5$)$ & 36.7 & $(35.1)$ & $0.6(0.5$ to 0.6$)$ & 18.4 & (11.8) & $0.8(0.7$ to 0.9$)$ \\
\hline Couple, unmarried & 50.4 & $(52.3)$ & $0.7(0.6$ to 0.8$)$ & 35.1 & $(36.8)$ & $0.7(0.6$ to 0.8$)$ & 14.6 & (10.9) & $0.9(0.6$ to 1.3$)$ \\
\hline \multicolumn{10}{|l|}{ Educational attainment } \\
\hline High school graduate & 42.0 & $(49.4)$ & 1.0 (referent) & 39.5 & $(39.5)$ & $1.2(1.1$ to 1.2$)$ & 18.5 & (11.2) & $2.0(1.9$ to 2.1$)$ \\
\hline Less than high school & 30.2 & $(36.8)$ & $1.5(1.4$ to 1.7$)$ & 31.7 & $(35.1)$ & $1.7(1.5$ to 1.9$)$ & 38.1 & $(28.1)$ & $2.5(2.3$ to 2.7$)$ \\
\hline \multicolumn{10}{|l|}{ Employment status } \\
\hline Employed/self employed & 44.5 & $(47.8)$ & 1.0 (referent) & 41.4 & $(41.0)$ & $1.1(1.0$ to 1.1$)$ & 14.0 & $(11.2)$ & $1.4(1.3$ to 1.5$)$ \\
\hline Unemployed & 41.7 & $(49.4)$ & $1.4(1.2$ to 1.6$)$ & 33.9 & $(34.6)$ & $1.6(1.4$ to 1.8$)$ & 24.3 & $(16.0)$ & $2.4(2.0$ to 2.9$)$ \\
\hline Student/homemaker & 44.1 & (53.2) & $0.9(0.8$ to 1.0$)$ & 36.7 & (33.8) & $1.2(1.1$ to 1.3$)$ & 19.2 & (13.0) & $1.6(1.4$ to 1.8$)$ \\
\hline Retired & 37.0 & (45.5) & $3.5(3.2$ to 3.7$)$ & 35.6 & (34.2) & $4.5(4.2$ to 4.8$)$ & 27.4 & (20.2) & $5.8(5.3$ to 6.3$)$ \\
\hline Unable to work & 20.3 & $(24.2)$ & $7.5(6.3$ to 8.9$)$ & 31.7 & (33.9) & $8.4(7.0$ to 10.0$)$ & 48.0 & $(41.9)$ & $10.4(9.0$ to 12.0$)$ \\
\hline \multicolumn{10}{|l|}{ Income } \\
\hline$<\$ 25000$ & 33.5 & $(43.1)$ & $1.6(1.5$ to 1.7$)$ & 35.9 & $(36.8)$ & $2.0(1.8$ to 2.1$)$ & 30.6 & $(20.1)$ & $3.1(2.9$ to 3.3$)$ \\
\hline$\$ 25000-\$ 49999$ & 42.1 & $(47.8)$ & $1.2(1.2$ to 1.3$)$ & 40.4 & $(40.1)$ & $1.4(1.3$ to 1.5$)$ & 17.5 & (12.0) & $2.0(1.9$ to 2.2$)$ \\
\hline$\geqslant \$ 50000$ & 48.7 & $(52.5)$ & 1.0 (referent) & 40.9 & $(40.6)$ & $1.1(1.0$ to 1.2$)$ & 10.4 & (7.0) & $1.6(1.4$ to 1.8$)$ \\
\hline \multicolumn{10}{|l|}{ Smoking status } \\
\hline Non-smoker & 38.5 & $(47.8)$ & 1.0 (referent) & 39.8 & $(39.4)$ & $1.3(1.2$ to 1.3$)$ & 21.7 & (12.9) & $2.1(2.0$ to 2.2$)$ \\
\hline Former smoker & 41.1 & $(48.5)$ & $1.9(1.8$ to 2.0$)$ & 37.7 & $(39.0)$ & $2.2(2.1$ to 2.3$)$ & 21.3 & (12.5) & $3.9(3.5$ to 4.2$)$ \\
\hline Current smoker & 41.9 & $(48.0)$ & $1.4(1.3$ to 1.5$)$ & 35.6 & $(38.1)$ & $1.5(1.4$ to 1.6$)$ & 22.5 & (13.9) & $2.6(2.4$ to 2.9$)$ \\
\hline \multicolumn{10}{|l|}{ Physically unhealthy days } \\
\hline 0 days & 44.6 & $(49.1)$ & 1.0 (referent) & 38.7 & $(38.2)$ & $1.1(1.1$ to 1.2$)$ & 16.7 & (12.8) & $1.4(1.4$ to 1.5$)$ \\
\hline $1-13$ days & 42.6 & (46.9) & $1.6(1.5$ to 1.7$)$ & 42.2 & $(42.5)$ & $1.8(1.7$ to 1.9$)$ & 15.2 & (10.7) & $2.6(2.4$ to 2.9$)$ \\
\hline $14-30$ days & 28.4 & (38.4) & $5.9(5.4$ to 6.5$)$ & 33.1 & (35.8) & $7.4(6.7$ to 8.2$)$ & 38.5 & $(25.9)$ & $11.9(10.7$ to 13.2$)$ \\
\hline \multicolumn{10}{|l|}{ Mentally unhealthy days } \\
\hline 0 days & 41.0 & (47.9) & 1.0 (referent) & 37.5 & $(38.1)$ & $1.2(1.1$ to 1.2$)$ & 21.5 & $(14.0)$ & $1.8(1.7$ to 1.9$)$ \\
\hline $1-13$ days & 42.2 & $(49.0)$ & $1.1(1.0$ to 1.1$)$ & 42.2 & $(42.0)$ & $1.2(1.2$ to 1.3$)$ & 15.6 & (9.0) & $2.2(1.9$ to 2.4$)$ \\
\hline $14-30$ days & 34.8 & $(46.2)$ & $2.2(2.0$ to 2.4$)$ & 35.6 & (37.2) & $2.8(2.5$ to 3.0$)$ & 29.6 & $(16.7)$ & $5.1(4.5$ to 5.7$)$ \\
\hline
\end{tabular}

underweight $(<18.5)$, normal weight $(18.5$ to $<25)$, overweight $(25$ to $<30)$, or obese $(\geqslant 30)]$; and smoking status (current (smoked at least 100 cigarettes and currently smoking), former (had smoked at least 100 cigarettes but not currently smoking), or never (never having smoked 100 cigarettes)).

Analysis was done using SUDAAN to account for the complex sample survey design and to incorporate sampling weights. The "recommended" category of PA was considered the referent exposure group. HRQOL (physically and mentally unhealthy days per month) was categorised in three levels: 0 days (the referent group), 1-13 days or moderately impaired HRQOL, and 14-30 unhealthy days or severely impaired HRQOL. We selected the 14 day cut off because this time period is often used by clinicians and clinical researchers as an indicator for clinical depression and anxiety disorders. With regard to physical health, increasing days of symptoms is associated with higher levels of activity limitations. ${ }^{17} \mathrm{~A}$ polytomous generalised multinominal logit model for nom- inal outcomes (PROC MULTILOG) was used to calculate sex specific crude and adjusted odds ratios (OR) and their 95\% confidence intervals (CI). Adjusted ORs controlled for the categorical covariates listed above, were chosen a priori and remained in the model regardless of their statistical significance because they can be associated with both HRQOL and physical activity level.

\section{RESULTS}

Of the 212000 respondents on the 2001 BRFSS representing 209 million adults aged 18 years and older, 33\% had arthritis. Among adults with arthritis, $40 \%$ reported meeting recommended levels of PA, 38\% had insufficient activity, and 22\% were inactive. Most reported no physically (51\%) and mentally $(61 \%)$ unhealthy days in the past 30 days. The odds of having arthritis were significantly increased for women, smokers, and those who were older, overweight, widowed or divorced, lesser educated, lower income, or nonworking persons. The odds were significantly decreased for 


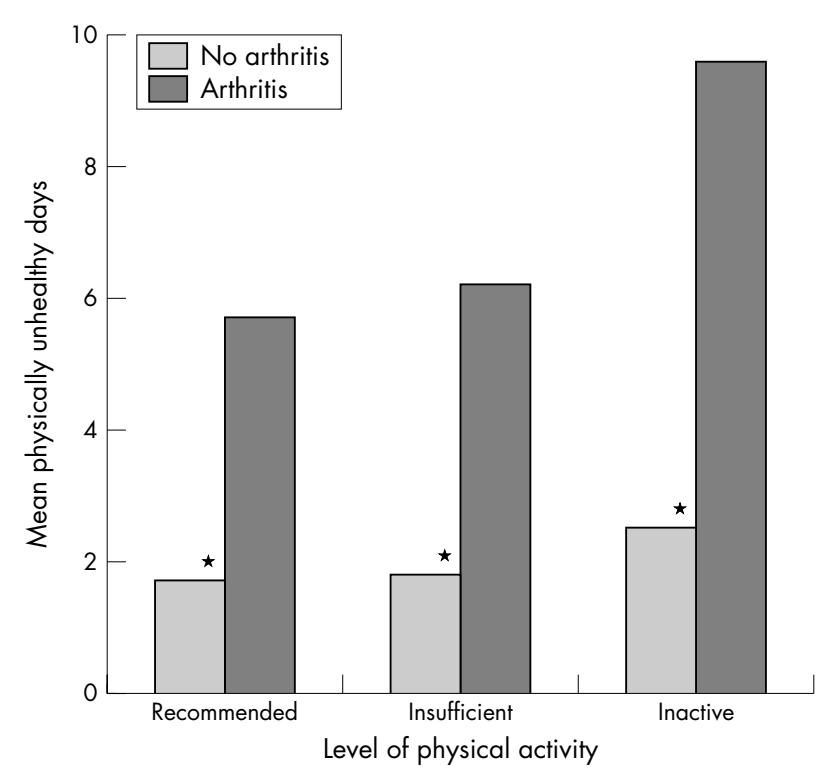

Figure 1 Mean physically unhealthy days by level of physical activity. *Denotes a significant difference $(p>0.05)$ between adults with and without arthritis.

races other than non-Hispanic white people and single persons/unmarried couples (table 1).

The prevalence of "recommended" PA among persons with arthritis ranged from $20.3 \%$ to $50.4 \%$ (table 2 ). One third or fewer of the obese, non-Hispanic black people, the widowed, the less educated, those unable to work, or those with 14-30 physically unhealthy days met "recommended" PA levels. Almost $50 \%$ of younger (18-44 years) respondents, couples (married or unmarried), and those with high income levels $(\geqslant \$ 50$ 000) met "recommended" PA levels. Older persons (age 65+), non-Hispanic black people, the widowed, the less educated, those unable to work, those with low incomes $(<\$ 25000)$, and those with 14-30 physically unhealthy days in the past 30 days were more often inactive $(30.6 \%-48.0 \%)$. For all characteristics, the odds of arthritis increased as PA levels decreased.

Respondents with arthritis had a mean of 6.7 physically unhealthy days during the past 30 days, compared with only 1.8 days among those without arthritis. Respondents with arthritis had a mean of 4.9 mentally unhealthy days during the past 30 days compared with 2.7 days in those without arthritis (data not shown). As PA level increased, respondents reported fewer physically (fig 1) and mentally (fig 2) unhealthy days.

In adjusted analyses of persons with arthritis, inactive men and women are 1.2 to 2.4 times more likely to have severely impaired (14-30 days/month) physically or mentally unhealthy days compared with those who meet PA recommendations (table 3). Men and women who engage in insufficient PA are also more likely to have severely impaired physical HRQOL. Insufficiently active men report moderately (1-13 days/month) but not severely impaired mental HRQOL.

\section{DISCUSSION}

In our study, participation in recommended amounts of physical activity in persons with arthritis was associated with fewer mean physically and mentally unhealthy days during the past 30 days and a decreased probability of having severely impaired physical or mental HRQOL. Groups with the highest prevalence of inactivity include persons aged 65 years and older, obese, non-Hispanic black people, widowed,

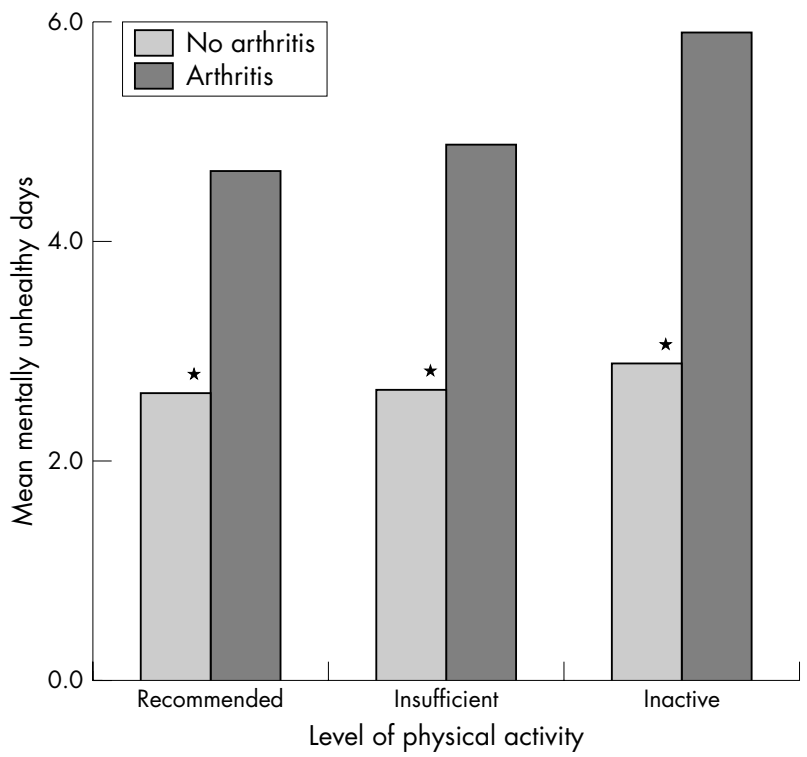

Figure 2 Mean mentally unhealthy days by level of physical activity. *Denotes a significant difference ( $>>0.05)$ between adults with and without arthritis.

less than high school education, income $<\$ 25000$, and those unable to work. To our knowledge, this is the first population based study that analysed the association between PA and HRQOL among persons with arthritis. The separate associations between PA and HRQOL, PA and arthritis, and arthritis and HRQOL have all been examined but not all three simultaneously. The study closest to examining this association $^{18}$ was a randomised controlled trial of exercise on mood and function in persons with fibromyalgia, in which exercise improved the mood of participants. Other studies in populations not selected for arthritis have also shown a positive effect of exercise on mood or quality of life. ${ }^{18-21}$ Physical activity has also been shown to decrease pain and disability associated with arthritis..$^{722}$

Persons with arthritis report worse HRQOL using the SF$36^{23}$ and a greater number of unhealthy days during the past 30 days than those without arthritis. In 2001, we found that persons with arthritis reported almost five more physically and 2.3 more mentally unhealthy days, on average, than those without arthritis. Those who met PA recommendations reported the fewest physically and mentally unhealthy days, those with insufficient PA slightly more, and inactive persons had the most unhealthy days. This trend was evident in persons with arthritis as well as in those without arthritis, although people with arthritis reported more unhealthy days than those without arthritis at all levels of PA. Increasing your level of PA may not only positively influence your general health but also may decrease the number of physically and mentally unhealthy days.

It is not surprising that active persons with arthritis have fewer physically and mentally unhealthy days than their less active counterparts. Among persons with arthritis, pain and functional limitation have been associated with decreased HRQOL, ${ }^{24}$ and regular aerobic and strengthening exercise improves physical health by decreasing pain, improving function, and delaying disease progression and its subsequent disability. ${ }^{72} 26$ Physical activity is also known to benefit mental and emotional health, both among the general population $^{2128}$ as well as among persons with arthritis. ${ }^{27} 29$ An aerobic exercise programme significantly decreased depression symptoms and improved pain and functional walking speed over 18 months among persons with knee 
Table 3 Crude and adjusted* association between level of physical activity and physically and mentally unhealthy days among persons with arthritis, BRFSS 2001

\begin{tabular}{|c|c|c|}
\hline & Insufficienł¥ & Inactiveł \\
\hline \multicolumn{3}{|l|}{$\begin{array}{l}\text { Women ( } n=41 \text { milliont) } \\
\text { Physically unhealthy days } \\
1-13 \text { days } \vee 0 \text { days }\end{array}$} \\
\hline Crude OR $(95 \% \mathrm{Cl})$ & 1.11 (1.02 to 1.20$)$ & 0.91 (0.81 to 1.02$)$ \\
\hline Adjusted $\mathrm{OR}^{*}(95 \% \mathrm{Cl})$ & $1.10(1.00$ to 1.21$)$ & $1.02(0.89$ to 1.17$)$ \\
\hline \multicolumn{3}{|c|}{$14-30$ days $\vee 0$ days (Physical) } \\
\hline Crude OR $(95 \% \mathrm{Cl})$ & $1.26(1.13$ to 1.40$)$ & 3.41 (3.06 to 3.81$)$ \\
\hline Adjusted $\mathrm{OR}^{*}(95 \% \mathrm{Cl})$ & $1.13(1.01$ to 1.28$)$ & 2.39 (2.04 to 2.79$)$ \\
\hline \multicolumn{3}{|l|}{ Mentally unhealthy days } \\
\hline \multicolumn{3}{|l|}{$1-13$ days $\vee 0$ days } \\
\hline Crude OR $(95 \% \mathrm{Cl})$ & 1.02 (0.93 to 1.11$)$ & $0.62(0.55$ to 0.70$)$ \\
\hline Adjusted $\mathrm{OR}^{*}(95 \% \mathrm{Cl})$ & 1.09 (0.99 to 1.21$)$ & 0.89 (0.76 to 1.04$)$ \\
\hline \multicolumn{3}{|c|}{ 14-30 days v 0 days (Mental) } \\
\hline Crude OR $(95 \% \mathrm{Cl})$ & $1.01(0.90$ to 1.13$)$ & 1.28 (1.14 to 1.44$)$ \\
\hline Adjusted $\mathrm{OR}^{*}(95 \% \mathrm{Cl})$ & $1.03(0.90$ to 1.17$)$ & 1.22 (1.05 to 1.43$)$ \\
\hline \multicolumn{3}{|l|}{ Men ( $\mathrm{n}=29$ milliont) } \\
\hline \multirow{2}{*}{\multicolumn{3}{|c|}{$\begin{array}{l}\text { Physically unhealthy days } \\
1-13 \text { days vs. } 0 \text { days }\end{array}$}} \\
\hline & & \\
\hline Crude OR (95\% Cl) & $1.12(1.00$ to 1.26$)$ & 0.96 (0.82 to 1.13$)$ \\
\hline Adjusted $\mathrm{OR}^{*}(95 \% \mathrm{Cl})$ & 1.13 (1.00 to 1.28$)$ & $0.96(0.81$ to 1.15$)$ \\
\hline \multicolumn{3}{|c|}{ 14-30 days $\vee 0$ days (Physical) } \\
\hline Crude OR (95\% Cl) & 1.41 (1.24 to 1.62$)$ & 3.74 (3.25 to 4.30$)$ \\
\hline Adjusted $\mathrm{OR}^{*}(95 \% \mathrm{Cl})$ & $1.30(1.11$ to 1.51$)$ & $2.19(1.84$ to 2.61$)$ \\
\hline \multirow{2}{*}{\multicolumn{3}{|c|}{$\begin{array}{l}\text { Mentally unhealthy days } \\
1-13 \text { days } \vee 0 \text { days (Mental) }\end{array}$}} \\
\hline & & \\
\hline Crude OR $(95 \% \mathrm{Cl})$ & $1.12(1.00$ to 1.26$)$ & 0.78 (0.67 to 0.92$)$ \\
\hline Adjusted $\mathrm{OR}^{*}(95 \% \mathrm{Cl})$ & $1.27(1.12$ to 1.44$)$ & $0.97(0.81$ to 1.16$)$ \\
\hline \multicolumn{3}{|c|}{$14-30$ days $\vee 0$ days (Mental) } \\
\hline & 1.21 (1.03 to 1.42$)$ & 2.15 (1.84 to 2.52$)$ \\
\hline Adjusted $\mathrm{OR}^{*}(95 \% \mathrm{Cl})$ & 1.19 (0.99 to 1.42$)$ & 1.56 (1.29 to 1.90$)$ \\
\hline
\end{tabular}

osteoarthritis. ${ }^{29}$ The most compliant participants (those who had the highest cumulative dose of exercise) reduced their depressive symptoms the most, again suggesting a link between dose of activity and beneficial mental outcomes for persons with arthritis. Despite this, people with arthritis are less active than their peers without arthritis ${ }^{10}$ and therefore one of the national Healthy People 2010 objectives is to increase the number of adults with arthritis that meet physical activity recommendations. ${ }^{30}$

People with arthritis are heterogeneous. Some have chronic and severe disease related limitations, while others have episodic pain and/or limitation. Severe and chronic limitations can surely worsen physical and mental HRQOL. To partially address this issue, although not reported here, we did conduct a subanalysis of respondents who reported arthritis but were not limited in any way in any of their daily activities as reported on the BRFSS survey. The strength of the association between PA and HRQOL was somewhat reduced among respondents with arthritis and no activity limitations, but higher levels of PA were still clearly associated with better HRQOL (data not shown). Physical activity interventions should therefore be designed for all of

\section{What this paper adds}

This study is unique in that it is the first time that physical activity, HRQOL, and arthritis have been investigated simultaneously on a population level. The results have important public health implications, specifically, increasing physical activity levels among people with arthritis may help improve long term HRQOL. Improving HRQOL may be one of the most important motivators for people with arthritis to become more physically active. those with arthritis, both those with and without activity limitations.

The most important limitation of this study is its cross sectional design that does not allow one to distinguish between cause and effect. In this case, poor physical or mental health may reduce levels of PA rather than reduced levels of PA causing poor physical or mental health. Secondly, because all information in this study is self reported, respondents may under-report or over-report physical activity and/or unhealthy days. However, any potential misclassification regarding self reported physical activity and HRQOL is unlikely to be differential because BRFSS asks about many health behaviours and outcomes, and it would be difficult for respondents to link select behaviours and outcomes. Thirdly, the biasing effect of non-response on sample representativeness is most probably small. ${ }^{31}$ Fourthly, the BRFSS collects minimal information on comorbid conditions. As the presence of comorbid conditions can greatly affect both your physically and mentally unhealthy days and your ability to remain physically active, such comorbidities may confound the associations reported here, particularly if these comorbid conditions are more common among those with arthritis. Lastly, although the BRFSS HRQOL measures do correlate with other more detailed assessments of HRQOL, they do not allow the respondent to distinguish in what domains their quality of life may be compromised.

The greatest strength of this study is the large, nationally representative sample of study subjects. Previous reports ${ }^{32}$ on arthritis and HRQOL using the BRFSS only reported data on 11 states. The 2001 BRFSS was the first year that data on physical activity, HRQOL, and arthritis were collected in all 50 states, the District of Columbia, and US territories. This substantial sample size has sufficient statistical power to show differences in HRQOL among those with arthritis and further permitted analysis of different PA levels. Other 
strengths of this study are that the HRQOL questions have been validated ${ }^{15} 16$ and that the physical activity and the arthritis modules have been cognitively tested and are currently being validated (CDC unpublished data). ${ }^{14}$

The BRFSS is an excellent population based source of data that can assist public health practitioners, clinicians, and health related organisations to monitor the prevalence of poor HRQOL among those with arthritis and to possibly assess the impact of interventions on their HRQOL. Longitudinal studies are needed to examine the natural history of PA and HRQOL among people with arthritis and to determine cause and effect. Rigorous clinical trials need to be conducted to assess whether increasing PA among people with arthritis to the recommended levels will delay the development and progression of impaired HRQOL. Future research should also develop and evaluate PA interventions that increase PA among those with arthritis, regardless of their functional status.

\section{Authors' affiliations}

J E Abell, Medical University of South Carolina, Charleston, South Carolina, USA

J M Hootman, M M Zack, D Moriarty, C G Helmick, Division of Adult and Community Health, National Center for Chronic Disease Prevention and Health Promotion, Centers for Disease Control and Prevention, Atlanta, Georgia, USA

Funding: none.

Competing interests: none declared.

Ethics approval: the behavioral risk factor surveillance system survey is reviewed and approved annually by the CDC Institutional Review Board.

\section{REFERENCES}

1 Centers for Disease Control and Prevention. Prevalence of disabilities and associated health conditions among adults-United States, 1999. Morb Mortal Wkly Rep 2001;50:120-5.

2 Arthritis Foundation, Centers for Disease Control and Prevention. National Arthritis Plan: a public health strategy. Atlanta, GA: Arthritis Foundation, 1999.

3 Centers for Disease Control and Prevention. Prevalence of self-reported arthritis or chronic joint symptoms among adults-United States, 2001. Morb Mortal Wkly Rep 2002;51:948-50.

4 Murphy L, Cisternas M, Yelin E, et al. Update: direct and indirect cost of arthritis and other rheumatic conditions-United States, 1997. Morb Mortal Wkly Rep 2004;53:388-9.

5 Centers for Disease Control and Prevention. Public health and aging: projected prevalence of self-reported arthritis or chronic joint symptoms among persons aged $\geqslant 65$ years - United States, 2005-2030. Morb Mortal Wkly Rep 2003;52:489-91

6 Mili F, Helmick CG, Zack MM, et al. Health-related quality of life among adults reporting arthritis: behavioral risk factor surveillance system, 15 states and Puerto Rico, 1996-1999. J Rheumatol 2003;30:160-6.

7 Ettinger WH, Burns R, Messier S, et al. A randomized trial comparing aerobic exercise and resistance exercise with a health education program in older adults with knee osteoarthritis: the fitness arthritis and seniors trial (FAST). JAMA 1997; 277:25-31.

8 American Geriatrics Society Panel on Exercise and Osteoarthritis. Exercise prescription for older adults with osteoarthritis pain: consensus practice recommendations. A supplement to the AGS clinical practice guidelines on the management of chronic pain in older adults. J Am Geriatr Soc 2001;49:808-23.
9 Ellingson T, Conn VS. Exercise and quality of life in elderly individuals. J Gerontol Nurs 2000;26:17-25.

10 Hootman J, Macera CA, Ham SA, et al. Physical activity levels among the general US population and in adults with and without arthritis. Arthritis Care Res 2003:49:129-35.

11 Centers for Disease Control and Prevention. Prevalence of leisure-time and occupational physical activity among employed adults - United States, 1990. Morb Mortal Wkly Rep 2000:49:420-4.

12 Pate R, Pratt M, Blair S, et al. Physical activity and public health. A recommendation from the Centers for Disease Control and Prevention and the American College of Sports Medicine. JAMA 1995;273:402-7.

13 American College of Sports Medicine. American College of Sports Medicine Position Stand. The recommended quantity and quality of exercise for developing and maintaining cardiorespiratory and muscular fitness, and flexibility in healthy adults. Med Sci Sports Exerc 1998;30:975-91.

14 Kimsey CD, Ham SA, Macera CA, et al. Reliability of moderate and vigorous physical activity questions in the behavioral risk factor surveillance system (BRFSS). Med Sci Sports Exerc 2003;35:S114.

15 Centers for Disease Control and Prevention. Measuring healthy days: population assessment of health-related quality of life. Atlanta, GA: US Department of Health and Human Services, Centers for Disease Control and Prevention, 2000.

16 Hennessy CH, Moriarty DG, Zack MM, et al. Measuring health-related quality of life for public health surveillance. Public Health Rep 1994; 109:665-72.

17 Milazzo-Sayer LJ, Henderson MJ, Manderscheid RW. Serious and severe mental illness and work: What do we know? In: Bonnie RJ, Monahan J, eds. Mental disorder, work disability, and the law. Chicago, IL: University of Chicago Press, 1997

18 Gowans SE, Voss S, Silaj A, et al. Effect of randomized, controlled trial of exercise on mood and physical function in individuals with fibromyalgia. Arthritis Rheum 2001;45:519-29.

19 US Department of Health and Human Services. Physical activity and health: a report of the Surgeon General. Atlanta, GA: US Department of Health and Human Services, Centers for Disease Control and Prevention, National Center for Chronic Disease Prevention and Health Promotion, 1996.

20 Blumenthal JA, Babyak MA, Moore KA, et al. Effects of exercise training on older patients with major depression. Arch Intern Med 1999;159:2349-56.

21 Stephens T. Physical activity and mental health in the United States and Canada: evidence from four population surveys. Prev Med 1988;17:35-47.

22 Spirduso WW. Exercise dose-response effects on quality of life and independent living in older adults. Med Sci Sports Exerc 2001;33:S598-608.

23 Miller ME, Rejeski WJ, Reboussin BA, et al. Physical activity, functional limitations, and disability in older adults. J Am Geriatr Soc 2000:48: 1264-72.

24 Hill CL, Parsons J, Taylor A, et al. Health related quality of life in a population sample with arthritis. J Rheumatol 1999;26:2029-35.

25 Jakobsson U, Hallberg I. Pain and quality of life among older persons with rheumatoid arthritis and/or osteoarthritis: a literature review. J Clin Nurs 2002;11:430-43.

26 Minor M. Exercise in the treatment of osteoarthritis. Rheum Dis Clin North Am 1999;25:397-415.

27 Rejeski J, Ettinger W, Martin K, et al. Treating disability in knee osteoarthritis with exercise therapy: a central role for self-efficacy and pain. Arthritis Care Res 1998;11:94-101.

28 Lawlor D, Hopker S. The effectiveness of exercise as an intervention in the management of depression: systemic review and meta-regression analysis of randomised, controlled trials. BMJ 2001;322:763-7.

29 Penninx B, Rejeski J, Pandya J, et al. Exercise and depressive symptoms: a comparison of aerobic and resistance exercise effects on emotional and physical function in older persons with high and low depressive symptomology. J Gerontol B Psych Sci Soc Sci 2002;57:124-32.

30 US Department of Health and Human Services. With understanding and improving health and objectives for improving health. In: Healthy People 2010. 2nd ed. Washington, DC: US Government Printing Office, 2000.

31 Keeter S, Miller C, Kohut A, et al. Consequences of reducing nonresponse in a national telephone survey. Public Opinion Q 2000;64:125-48.

32 Centers for Disease Control and Prevention. Health-related quality of life among adults with arthritis-behavioral risk factor surveillance system, 11 states, 1996-1998. Morb Mortal Wkly Rep 2000;49:366-9. 